\title{
Indoor and outdoor malaria transmission in two ecological settings in rural Mali: implications for vector control
}

\author{
Moussa Keïta1, 1,3,4*, Sidy Doumbia 1,2, Ibrahim Sissoko ${ }^{1,2}$, Mahamoudou Touré ${ }^{1,2}$, Sory Ibrahim Diawara 1,2, \\ Drissa Konaté1,2, Ambièlè Bernard Sodio ${ }^{4}$, Sekou F. Traoré ${ }^{1,2}$, Mahamadou Diakité1,2, Seydou O. Doumbia 1,2,3, \\ Nafomon Sogoba ${ }^{1,2,3}$, Donald J. Krogstad ${ }^{5}$, Jeffrey G. Shaffer ${ }^{5}$ and Mamadou B. Coulibaly ${ }^{1,2}$
}

\begin{abstract}
Background: Implementation and upscale of effective malaria vector control strategies necessitates understanding the multi-factorial aspects of transmission patterns. The primary aims of this study are to determine the vector composition, biting rates, trophic preference, and the overall importance of distinguishing outdoor versus indoor malaria transmission through a study at two communities in rural Mali.

Methods: Mosquito collection was carried out between July 2012 and June 2016 at two rural Mali communities (Dangassa and Koïla Bamanan) using pyrethrum spray-catch and human landing catch approaches at both indoor and outdoor locations. Species of Anopheles gambiae complex were identified by polymerase chain reaction (PCR). Enzyme-Linked -Immuno-Sorbent Assay (ELISA) were used to determine the origin of mosquito blood meals and presence of Plasmodium falciparum sporozoite infections.

Results: A total of 11,237 An. gambiae sensu lato (s.l.) were collected during the study period (5239 and 5998 from the Dangassa and Koïla Bamanan sites, respectively). Of the 679 identified by PCR in Dangassa, Anopheles coluzzii was the predominant species with $91.4 \%$ of the catch followed by An. gambiae (8.0\%) and Anopheles arabiensis (0.6\%). At the same time in Koïla Bamanan, of the 623 An. gambiae s.l., An. coluzzii accounted for $99 \%$ of the catch, An. arabiensis 0.8\% and An. gambiae 0.2\%. Human Blood Index (HBI) measures were significantly higher in Dangassa (79.4\%; 95\% Bayesian credible interval (BCI) [77.4, 81.4]) than in Koïla Bamanan (15.9\%; 95\% BCI [14.7, 17.1]). The human biting rates were higher during the second half of the night at both sites. In Dangassa, the sporozoite rate was comparable between outdoor and indoor mosquito collections. For outdoor collections, the sporozoite positive rate was 3.6\% (95\% BCl [2.1-4.3]) and indoor collections were 3.1\% (95\% BCl [2.4-5.0]). In Koïla Bamanan, the sporozoite rate was higher indoors at 4.3\% (95\% BCI [2.7-6.3]) compared with outdoors at 2.4\% (95\% BCI [1.1-4.2]). In Dangassa, corrected entomological inoculation rates (CEIRs) using HBI were 13.74 [95\% BCI 9.21-19.14] infective bites/person/month $(\mathrm{ib} / \mathrm{p} / \mathrm{m})$ at indoor, and $18.66[95 \% \mathrm{BCl} 12.55-25.81] \mathrm{ib} / \mathrm{p} / \mathrm{m}$ at outdoor. For Koïla Bamanan, cEIRs were 1.57 [95\% BCl $2.34-2.72] \mathrm{ib} / \mathrm{p} / \mathrm{m}$ and 0.94 [95\% BCl 0.43-1.64] ib/p/m for indoor and outdoor, respectively. ElRs were significantly higher at the Dangassa site than the Koïla Bamanan site.
\end{abstract}

*Correspondence: moussa@icermali.org

${ }^{1}$ West African International Center of Excellence for Malaria Research, Bamako, Mali

Full list of author information is available at the end of the article

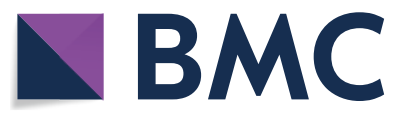

(c) The Author(s) 2021. This article is licensed under a Creative Commons Attribution 4.0 International License, which permits use, sharing, adaptation, distribution and reproduction in any medium or format, as long as you give appropriate credit to the original author(s) and the source, provide a link to the Creative Commons licence, and indicate if changes were made. The images or other third party material in this article are included in the article's Creative Commons licence, unless indicated otherwise in a credit line to the material. If material is not included in the article's Creative Commons licence and your intended use is not permitted by statutory regulation or exceeds the permitted use, you will need to obtain permission directly from the copyright holder. To view a copy of this licence, visit http://creativeco mmons.org/licenses/by/4.0/. The Creative Commons Public Domain Dedication waiver (http://creativecommons.org/publicdomain/ zero/1.0/) applies to the data made available in this article, unless otherwise stated in a credit line to the data. 
Conclusion: The findings in this work may indicate the occurrence of active, outdoor residual malaria transmission is comparable to indoor transmission in some geographic settings. The high outdoor transmission patterns observed here highlight the need for additional strategies to combat outdoor malaria transmission to complement traditional indoor preventive approaches such as long-lasting insecticidal nets (LLINs) and indoor residual spraying (IRS) which typically focus on resting mosquitoes.

Keywords: Malaria transmission, Outdoor, An. gambiae complex, Entomological Inoculation Rate (EIR), Pyrethrum spray catch, Human landing catch

\section{Background}

Malaria transmission is heterogeneous and heavily dependent on the local climatic and eco-geographical conditions. Variations are commonly observed at both the village and household levels [1,2]. Vector control relies mainly on large-scale indoor residual spraying (IRS) and bed net distribution, both being recommended by the World Health Organization [3]. With proper implementation, these approaches have been shown to be highly effective in reducing human-mosquito contact and the burden of malaria [4-7]. In fact, IRS played a central role in the ultimate eradication of malaria in Europe in the 1950s [8], and recent elimination in some African countries [9]. Distribution of long-lasting insecticidal nets (LLINs) was a main driver for the decline in malaria incidence between 2000 and 2015, accounting for an estimated $68 \%$ of the 663 million clinical cases averted over this time period [5]. Anopheles coluzzii, Anopheles gambiae sensu stricto (s.s.) and Anopheles arabiensis, that belong to the Anopheles gambiae complex, and the Anopheles funestus group are the predominant malaria vectors in Mali. Anopheles gambiae+ and An. coluzzii, two of the four major malaria vectors in Africa, have been described as being mainly endophagic and endophilic [10-14]. There is increasing evidence of a decline in both endophagic and endophilic behaviour in the $A n$. gambiae s.s. and An. coluzzii populations after the introduction of IRS and LLINs $[15,16]$. Because they both target indoor biting and resting mosquitoes, their use over time and across space might have led to behavioural changes in vector populations [16-19]. The reaction of the mosquito populations to these indoor-use control strategies has jointly led to declining endophilic behavioural activity and increased outdoor biting rates. This phenomenon can be exacerbated in tropical areas where, due to high temperatures, human populations tend to remain outdoors for longer periods of time and are bitten before sheltering indoors. Therefore, it appears that current control strategies focusing on indoor-based methods may not be enough to eliminate malaria transmission in most endemic countries [20,21]. Hence it is necessary to understand the importance, ecology and dynamics of outdoor transmission to develop and implement appropriate outdoor control methods. The objectives of this study were, therefore, to investigate potential changes in vector species composition, feeding behaviour and contribution to indoor and outdoor malaria transmission in two ecologically different situated in rural parts of Mali.

\section{Methods}

Study sites

Data was obtained from longitudinal mosquito population surveys conducted at two sites in Mali, the villages of Dangassa and Koïla Bamanan located in two distinct ecological settings (Fig. 1). At each study village, longitudinal surveys were carried out during 12-day field visits at the beginning (June-July), middle (August), the end (October) of the rainy season; and in the dry season (April) from 2012 to 2016.

Dangassa $\left(8^{\circ} 12^{\prime} 37.253^{\prime \prime} \mathrm{W}\right.$ and $\left.12^{\circ} 8^{\prime} 46.279^{\prime \prime} \mathrm{N}\right)$ is located in the health district of Ouéléssébougou, $75 \mathrm{~km}$ away south of Bamako. Between the fringe of the village and the river Niger, lays a plain of about $1 \mathrm{~km}$ that floods in the rainy season. It is used for rice cultivation in the rainy season and vegetables gardening in the dry season. This is a Sudanian eco-geographical zone with a rainy season lasting from June to October and a dry season from November to May. The annual mean rainfall from 2012 to 2016 was $947.92 \mathrm{~mm}$. The dominant winds are the monsoon (rainy season) and the harmattan (dry season).

Koïla Bamanan $\left(5^{\circ} 45^{\prime} 32.18^{\prime \prime} \mathrm{W}\right.$ and $\left.13^{\circ} 38^{\prime} 24.026^{\prime \prime} \mathrm{N}\right)$ in the health district of Dioro, is located about $385 \mathrm{~km}$ south-east of Bamako. This is a Sahelian eco-geographical zone with a rainy season from July to October with about 250-500 $\mathrm{mm}$ of rain per year and a dry season from November to May. Koïla Bamaman is located in an irrigated area where controlled submersion rice cultivation is practiced. The dominant winds are the monsoon (rainy season) and the harmattan (dry season).

According to the 2012 Demographic and Health Survey (DHS) in Mali, the prevalence of malaria among children under 5 years old was $52 \%$ based on microscopy and $47 \%$ based on rapid diagnostic tests (RDTs) [22]. Plasmodium falciparum parasites accounted for $85-90 \%$ of malaria 


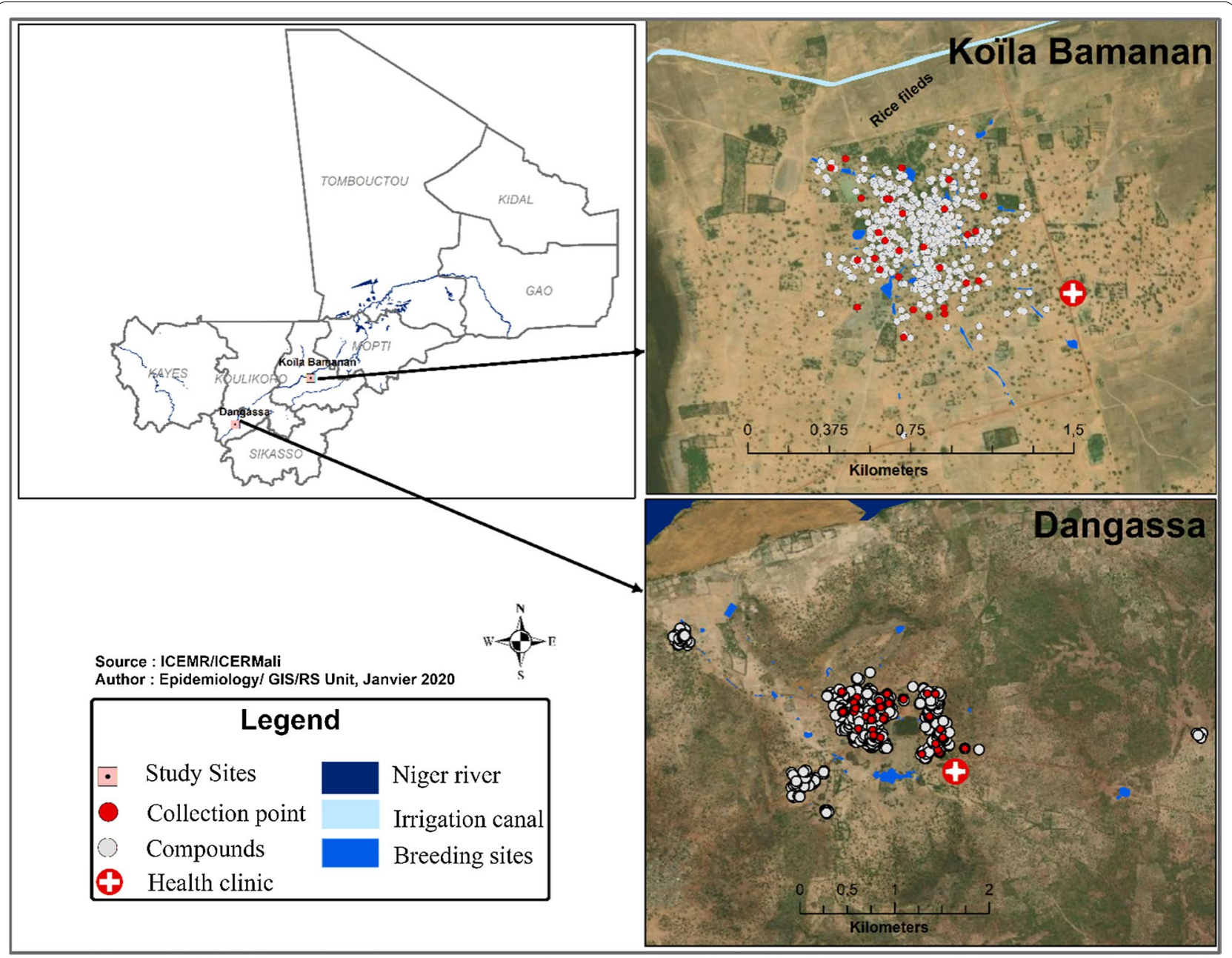

Fig. 1 Map showing the study sites

infections, while other parasite types included Plasmodium malariae (10-14\%) and Plasmodium ovale (1\%). Anopheles gambiae sensu lato (s.l.) (An. coluzzii, An. gambiae, An. arabiensis) and An. funestus group are currently the main vectors in Mali. In all the villages' malaria control core intervention are chemoprevention by intermittent preventive treatment (IPT) in pregnant women and seasonal malaria chemoprevention (SMC) in children from 3 to 59 months, the use of long-lasting insecticidal nets (LLINs).

\section{Mosquito collection}

Two collection methods were used for adult mosquitoes sampling: pyrethrum spray catch (PSC) and human landing catch (HLC). In total, 12 different surveys in each village over 5 years (2012-2016) were performed. During each survey, three rounds of HLC were set up with two collection points. Two volunteers (one indoor and one outdoor) collected mosquitoes at each of the two points making a total collection effort of 12 man-nights per survey. The collection sessions occurred from 18:00 $\mathrm{h}$ to $06: 00 \mathrm{~h}$ indoors and outdoors in two randomly selected rooms. Collected mosquitoes were kept in separate cups, labelled by collection night, location and collection and time point. The volunteers rotated between indoor and outdoor positions after every hour to account for any biases due to variability in the attractiveness of individuals to mosquitoes $[23,24]$. Volunteers were selected among young adult males at least 18 years old from the study site communities. The volunteers were trained prior to data collection periods and were informed about the study risks before agreeing to participate. Volunteers were offered treatment if they presented to health centers with malaria symptoms during the study. Informed consent was sought from room owners or users for the mosquito collections as the collections involved overnight stays. The collected specimens on human baits were 
morphologically identified $[13,14]$. All these operations were supervised by two experienced entomologists.

During each survey, three sessions of PSC were conducted in the rooms to collect indoor resting mosquitoes from 07:00 $\mathrm{h}$ to 09:00 $\mathrm{h}$ according to the World Health Organization (WHO) standard protocol [25]. After each session, the collected mosquitoes were sorted according to their abdominal status (unfed, fed, half-gravid, and gravid) and dissected in two portions (head-thorax and abdomen) for the laboratory process. Each mosquito was kept in a labeled $1.5 \mathrm{ml}$ eppendorf tube containing $80 \%$ ethanol. Samples were stored at $-20{ }^{\circ} \mathrm{C}$ freezer in the laboratory until used for further processing.

\section{Laboratory analysis of mosquitoes}

The species composition of An. gambiae complex was determined by PCR [26]. The blood meal sources of freshly fed and half gravid Anopheles were analysed by a direct enzyme-linked immunosorbent assay (ELISA) using human antibodies [27]. Head and thorax portions of the preserved Anopheles specimens were tested for $P$. falciparum circumsporozoite proteins (CSPs) using the ELISA technique [28].

\section{Data management and analysis}

Data were entered in StudyTRAX database management system (version v3.2.0802, StudyTRAX, Macon, GA). The Win BUGS application (version 1.4.1) was used to analyse the data. Pearson's Chi square tests were used to compare proportions (species composition). The mosquito density, the human biting rates, the human blood index, the $P$. falciparum infection rates and the entomological inoculation rates were estimated using formulas in Table 1 [29]. Bayesian credible intervals (BCI) were also used to compare the proportions. All analyses were carried out with a 5\% type I error threshold.

\section{Ethics approval and consent to participate}

This study was approved by the Institutional Review Board of Tulane University (11-255609) and the Ethics Committee of the Faculty of Medicine and Faculty of Pharmacy (FMPOS) at the University of Sciences,
Techniques and Technologies of Bamako (USTTB) in Mali (2011/77/FMPOS). In each of the villages, community consent had been obtained prior to the occurrence of any study activities. Individual informed consent forms were obtained for PSCs and HLCs (for both room owners and data collectors) before starting mosquito collections.

\section{Results}

Anopheles mosquito species composition and abundance During the study period, a total of 11,237 An. gambiae s.l. females were collected by PSC and HLC approaches. Among these specimens, $46.6 \%(5239 / 11,237)$ were collected in Dangassa and 53.4\% $(5998 / 11,237)$ in Koïla Bamanan. Based on logistics and practical considerations, a sub-sample was randomly selected across surveys to conduct molecular species identification. Of the 679 identified by PCR in Dangassa, An. coluzzii was the predominant species with a prevalence of $91.4 \%$ followed by An. gambiae (8.0\%) and An. arabiensis (<1\%). In Koïla Bamanan, 623 An. gambiae s.l. were identified by the same methods and An. coluzzii represented 99\%, An. arabiensis $0.8 \%$ and An. gambiae $0.2 \%$ of the catches. Overall, the An. coluzzii frequency was higher in Koïla Bamanan (99\%) than in Dangassa $(91.4 \%)\left(\chi^{2}=38.99\right.$, $\mathrm{P}<.001)$. No significant difference was observed between the frequencies of An. arabiensis $\left(\mathrm{X}^{2}=0.001, \mathrm{P}=0.970\right)$ and An. gambiae $\left(\mathrm{X}^{2}=0.081, \mathrm{P}=0.770\right)$ at both sites.

\section{Density and human blood index}

In terms of abundance, Fig. 2 shows the monthly mean densities of An. gambiae s.l. in both localities using the PSC method. The mean density of An. gambiae s.l. over the entire study period was 12.8 [95\% BCI 12.5-13.2] per room in Koïla Bamanan and 6.4 [95\% BCI 6.2-6.7] per room in Dangassa. The highest densities were observed in April and August of 2014 for both villages. However, the densities of Koilla Bamanan were considerably higher than those of Dangassa. The lowest densities were observed in April 2016 for both study sites.

Over the 12 surveys, the mean HBIs of An. gambiae s.l. for Dangassa and Koilla Bamanan were $79.4 \%$ and $15.9 \%$, respectively (Fig. 2). In Dangassa, the highest HBI was

Table 1 Formulas used to calculate the entomological parameters

\begin{tabular}{|c|c|}
\hline Entomological parameters & Formula \\
\hline Densities of female mosquitoes per room & Total number of collected mosquitoes/total number of rooms \\
\hline Human blood index & (Total number of positive in ELISA for human blood/total number of tested mosquitoes) $\times 100$ \\
\hline Human biting rates (HLC) & Total number of collected mosquitoes/(total number of volunteers x number of rounds) \\
\hline Human biting rates (PSC) & $\begin{array}{l}\text { Total number of freshly fed mosquitoes/number of residents that have slept in the rooms the } \\
\text { previous night }\end{array}$ \\
\hline Sporozoite infection rate in mosquitoes & (Total positive in ELISA/total tested) × 100 \\
\hline Entomological Inoculation Rates (HLC and PSC) & HBR $\times($ Total positive in ELISA/total tested $)$ \\
\hline
\end{tabular}



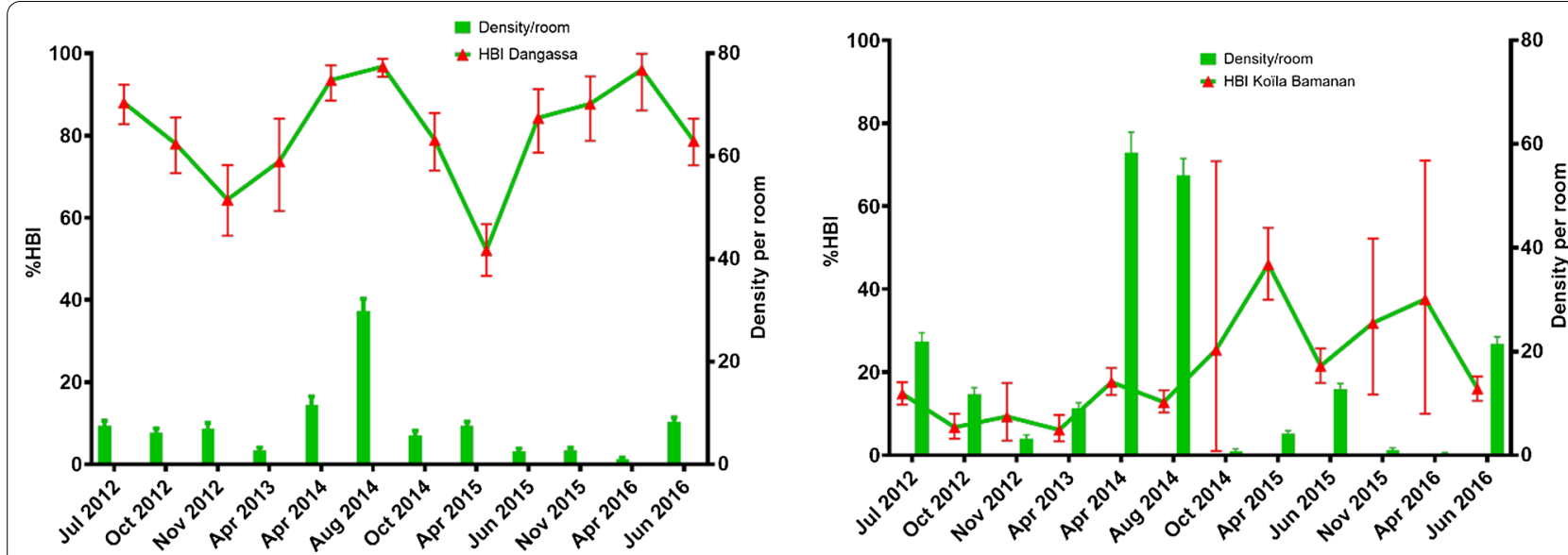

Fig. 2 Monthly mean density (MMD) and human blood index (HBI) of An. gambiae s.l. in human dwellings in Dangassa \& Koïla Bamanan from 2012 to 2016

observed in August 2014 (96.8\%) and the lowest HBI (52.1\%) in April 2015, while in Koïla Bamanan, the lowest $(6.7 \%)$ was observed in October 2012 and the highest (46.0\%) in April 2015. HBIs were significantly higher in Dangassa than in Koïla Bamanan $\left(X^{2}=1913.6, \mathrm{P}<0.001\right)$ during the entire study period.

\section{Monthly human biting rates (MHBRs), sporozoite infection} rates (SIR) and entomological inoculation rates (EIRs)

Figure 3 shows the human biting rates and the entomological inoculation rates from PSC in Dangassa and Koïla Bamanan respectively. The average monthly human biting rate (MHBR) was 2.3 times higher in Koïla Bamanan (69.8 bites/person/month) than in Dangassa $(30 \mathrm{~b} / \mathrm{p} / \mathrm{m})$. Monthly variations in MHBRs were observed at both sites. The highest MHBRs were recorded in April and August 2014. However, they were higher in Koilla
Bamanan (266.6 and $249.6 \mathrm{~b} / \mathrm{p} / \mathrm{m})$ than in Dangassa $(65.9$ and $105.5 \mathrm{~b} / \mathrm{p} / \mathrm{m}$ ) (Fig. 3).

There was no significant difference in overall (over the entire study period) sporozoite infection rates (SIR) between the two study sites (infection rates were $2.9 \%$, [95\% BCI 2.3-3.6 for Dangassa versus 2.6\% [95\% BCI 2.2-3.1] for Koïla Bamanan; Table 2). Monthly and annual variations were observed at both sites. In Dangassa, the highest SIRs were observed in October (8.9\%) in both 2012 and October 2014 (5.9\%). The peaks of the infection rates were observed in October in both Dangassa Koïla Bamanan. In Koïla Bamanan, in addition to the peak in October (6.4\% in 2014), there was a second peak that was observed in April (7.1\% in 2014 and $78.5 \%$ in 2016).

Given the fact that mosquitoes can feed on different hosts, to have a correct estimation of the EIR, we

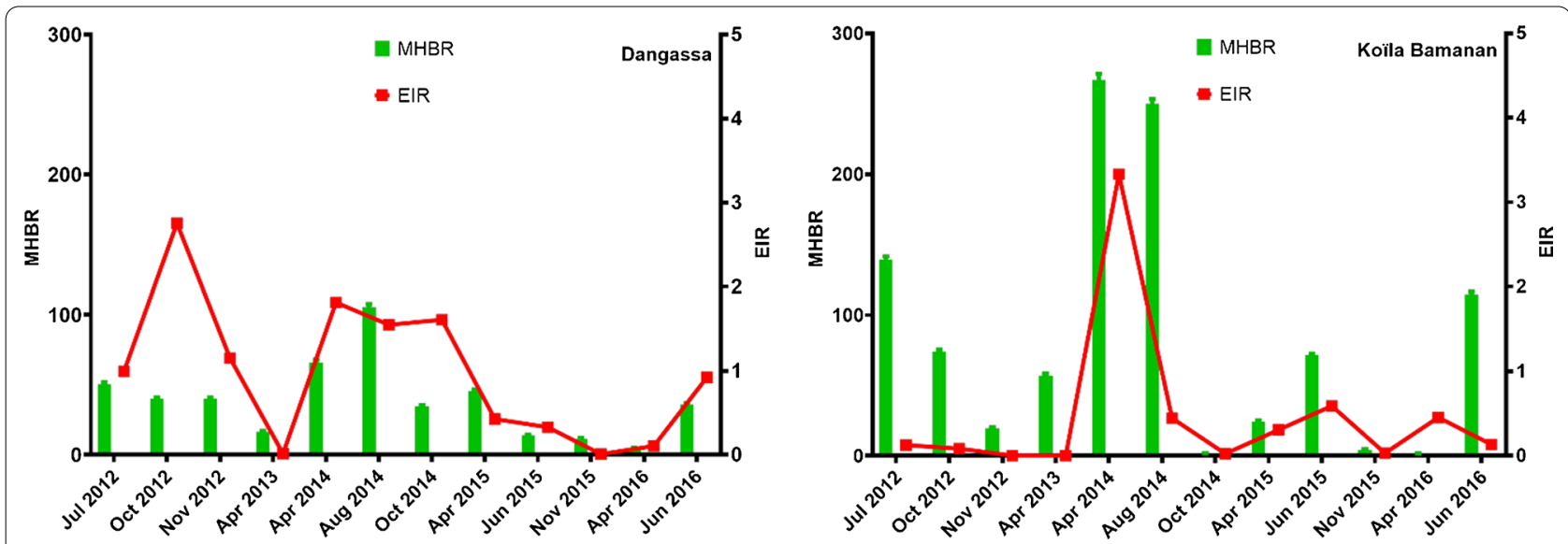

Fig. 3 Monthly human biting rate (MHBR) and entomological inoculation rate (EIR) of Anopheles gambiae s.l. mosquitoes collected by spray-catch from Dangassa and Koïla Bamanan form July 2012 to June 2016 
Table 2 Sporozoite infection rate (SIR) and entomological inoculation rate (EIR) of Anopheles gambiae s.I. mosquitoes collected by spray-catch from Dangassa and Koïla Bamanan form July 2012 to June 2016

\begin{tabular}{|c|c|c|c|c|c|c|c|c|c|c|}
\hline \multirow[t]{2}{*}{ Survey } & \multicolumn{5}{|c|}{ Dangassa } & \multicolumn{5}{|c|}{ Koïla Bamanan } \\
\hline & \#Tested & IR (\%) & $\mathrm{BCl}$ & EIR & $\mathrm{BCl}$ & \#Tested & IR (\%) & $\mathrm{BCl}$ & EIR & $\mathrm{BCl}$ \\
\hline Jul 2012 & 226 & 2.2 & {$[0.7-4.5]$} & 0.99 & [0.33-2.01] & 656 & 0.6 & {$[0.2-1.3]$} & 0.13 & [0.04-0.28] \\
\hline Oct 2012 & 181 & 8.9 & {$[5.2-13.4]$} & 2.75 & {$[1.61-4.17]$} & 351 & 1.7 & {$[0.6-3.3]$} & 0.09 & [0.03-0.16] \\
\hline Nov 2012 & 224 & 4.5 & {$[2.2-7.5]$} & 1.15 & {$[0.56-1.94]$} & 96 & 0.1 & {$[0.0-1.1]$} & 0.00 & {$[0.00-0.02]$} \\
\hline Apr 2013 & 81 & 0.1 & [0.0-1.3] & 0.01 & {$[0.00-0.15]$} & 269 & 0.0 & {$[0.0-0.4]$} & 0.00 & {$[0.00-0.01]$} \\
\hline Apr 2014 & 171 & 2.9 & [1.0-5.9] & 1.81 & {$[0.60-3.66]$} & 875 & 7.1 & [5.5-8.9] & 3.33 & [2.57-4.17] \\
\hline Aug 2014 & 596 & 1.5 & {$[0.7-2.6]$} & 1.55 & [0.72-2.69] & 1078 & 1.4 & {$[0.8-2.2]$} & 0.45 & {$[0.25-0.70]$} \\
\hline Oct 2014 & 169 & 5.9 & [2.9-9.9] & 1.61 & [0.79-2.71] & 16 & 6.4 & {$[0.2-22.1]$} & 0.03 & [0.00-0.09] \\
\hline Apr 2015 & 337 & 1.8 & {$[0.7-3.5]$} & 0.43 & {$[0.16-0.82]$} & 183 & 2.8 & {$[0.9-5.6]$} & 0.31 & [0.10-0.62] \\
\hline Jun 2015 & 141 & 2.9 & {$[0.8-6.2]$} & 0.33 & [0.09-0.72] & 572 & 3.9 & {$[2.4-5.6]$} & 0.59 & [0.37-0.86] \\
\hline Nov 2015 & 121 & 0.1 & {$[0.0-0.9]$} & 0.01 & {$[0.00-0.09]$} & 47 & 2.2 & {$[0.1-7.9]$} & 0.03 & {$[0.00-0.11]$} \\
\hline Apr 2016 & 46 & 2.3 & {$[0.1-8.0]$} & 0.11 & {$[0.00-0.36]$} & 14 & 78.5 & [54.5-94.9] & 0.45 & {$[0.31-0.58]$} \\
\hline Jun 2016 & 369 & 3.3 & [1.7-5.3] & 0.92 & {$[0.48-1.50]$} & 963 & 0.7 & {$[0.3-1.4]$} & 0.13 & {$[0.05-0.25]$} \\
\hline Total & 2662 & 2.9 & {$[2.3-3.6]$} & 0.70 & {$[0.56-0.86]$} & 5120 & 2.6 & {$[2.2-3.1]$} & 0.29 & {$[0.24-0.34]$} \\
\hline
\end{tabular}

multiplied it by the proportion of mosquitoes which have taken their blood meal on human following the ELISA test. This correction is especially required when the human blood index is less $60 \%$. The mean EIR was significantly higher in Dangassa (0.70 infective bites/ person $/$ month $=\mathrm{ib} / \mathrm{p} / \mathrm{m})$ than in Koilla Bamanan $(0.29$ $\mathrm{ib} / \mathrm{p} / \mathrm{m}$; Fig. 3). In Dangassa, the highest monthly EIRs were observed during the months of October 2012, April and October 2014, (2.75; 1.81 and $1.61 \mathrm{ib} / \mathrm{p} / \mathrm{m})$. In Koïla Bamanan, the highest EIRs were recorded for April 2014 and June 2015 (3.33 and $0.59 \mathrm{ib} / \mathrm{p} / \mathrm{m}$, respectively). As with the sporozoite infection rates, EIRs also were subject to monthly and annual variations.

\section{Outdoor vs indoor biting activities of An. gambiae s.l. in Dangassa and Koïla Bamanan}

Data for comparing the location of biting activities (indoor versus outdoor locations) were generated using mosquitoes collected by human landing catches. Hourly variation of HBRs showed a wide patterns of variation for both indoor and outdoor locations in both villages (Fig. 4).

Figure 4 shows HBR per hour and by season. HBR was higher during the second part of the night indoors and outdoors regardless of site and season. A peak of HBR was observed outdoors between 02:00 $\mathrm{h}$ and 03:00 $\mathrm{h}$, and then two peaks respectively between 01:00 $\mathrm{h}-02: 00 \mathrm{~h}$ and 04:00 $\mathrm{h}-05: 00 \mathrm{~h}$ during the rainy season at Dangassa (Fig. 4a). In the dry season, the peak was observed between 02:00 $\mathrm{h}$ and 04:00 $\mathrm{h}$, but it was lower than in the wet season (Fig. 4b). At Koila Bamanan, two peaks were observed indoor during the rainy season, where the first occurred between 23:00 $\mathrm{h}$ and 00:00 $\mathrm{h}$, and the second occurred between 01:00 $\mathrm{h}$ and 02:00 h (Fig. 4c). In the dry season, a single peak was observed between 23:00 $\mathrm{h}$ and 00:00 $\mathrm{h}$ indoor and outdoor at Koïla Bamanan (Fig. 4d).

In Dangassa, the highest MHBRs were observed in July, October and November 2012, and in April and August 2014 (Fig. 5). The average HBR over the study period was significantly higher outdoors $(648.9 \mathrm{~b} / \mathrm{p} / \mathrm{m}$ [BCI 642.6-655.2]) than indoors $(560.3 \mathrm{~b} / \mathrm{p} / \mathrm{m}$ [BCI 554.7-565.9]) suggesting an exophagic coefficient of 1.2 (648.9/560.3).

In Koïla Bamanan, the highest MHBRs were observed in October 2012, April and August 2014 and in June 2016 indoor and outdoor (Fig. 5). As observed in Dangassa, in Koila Bamanan the average HBR over the study period was significantly higher for outdoor locations $(242.4 \mathrm{~b} / \mathrm{p} / \mathrm{m}$ [BCI 238.1-246.7]) than indoor locations $(228.9 \mathrm{~b} / \mathrm{p} / \mathrm{m}$ [BCI 225.1-232.6]) with an exophagic coefficient of 1.1 (242.4/228.9). HBRs were significantly higher in Dangassa than in Koïla Bamanan, both indoors and outdoors.

In Dangassa, the sporozoite infection rate in $A n$. gambiae s.l. was 3.1\% [BCI 2.1-4.3] and 3.6\% [BCI 2.4-5.0] for indoor and outdoor locations, respectively. No significant differences were observed between these two rates. The sporozoite infection rates were subject to wide month-to-month variability. In Koïla Bamanan, the average sporozoite infection rate was 4.3\% [95\% BCI 2.7-6.3] and 2.4\% [95\% BCI 1.1-4.2] for indoor and outdoor locations, respectively. The sporozoite infection rate indoors was 1.8 times higher 
a Rainy season

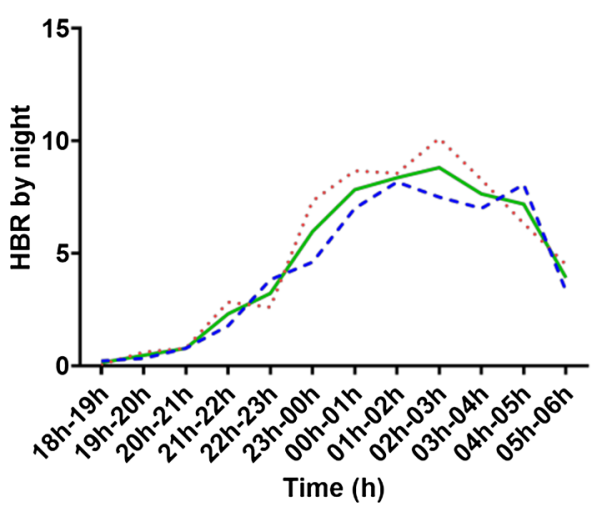

- Both indoor and outdoor

C Rainy season

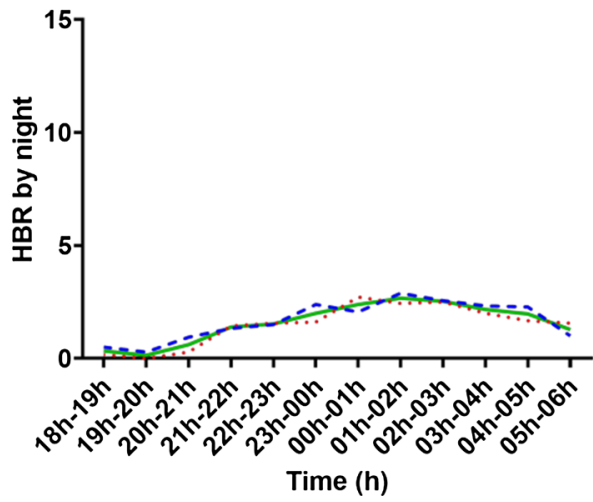

b Dry season

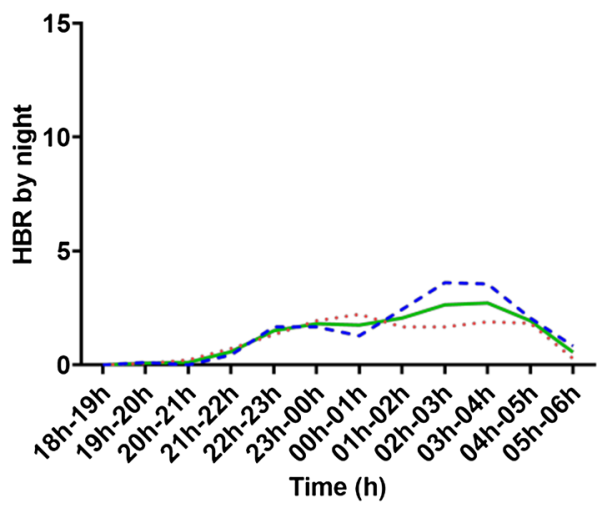

- MBR Indoor . . MBR Outdoor

d Dry season

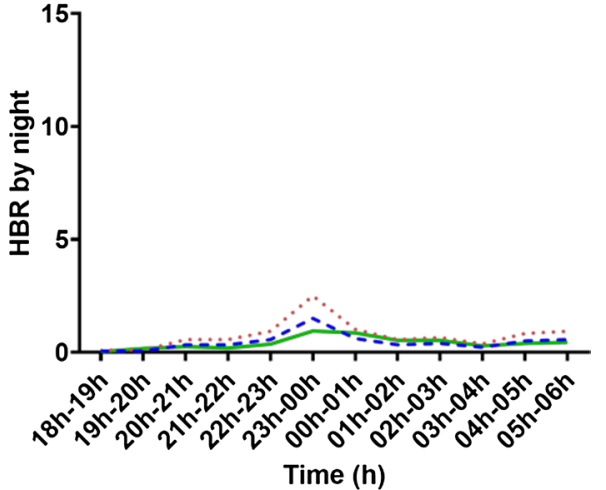

Fig. 4 Hourly biting activity of An. gambiae s.l in Dangassa (a and $\mathbf{b}$ ) and Koïla Bamanan (c and $\mathbf{d}$ ) during study period by season. Rainy season covers June to October and dry season covers November to May

than outdoors, though no significant difference was observed between the two. Similar monthly variations were observed both indoors and outdoors for Dangassa (Table 3).

EIRs showed monthly variations (Fig. 5). In Dangassa, the EIRs were estimated to be 13.74 [BCI 9.2119.14] and 18.66 [BCI 12.55-25.81] ib/p/m, for indoor and outdoor locations, respectively. The EIR was 1.4 times higher outdoors than indoors, though the difference was not significant. The highest rates were observed in July and October 2012. In Koïla Bamanan, EIRs were 1.57 [BCI 2.34-2.72] and 0.94 [BCI 0.43$1.64 \mathrm{ib} / \mathrm{p} / \mathrm{m}$ for indoor and outdoor locations, respectively. The highest rates were observed for August 2014 and June 2015. In contrast to Dangassa, the EIR was 1.7 times higher indoors than outdoors. However this difference was not significant.

\section{Discussion}

Vector control remains a critical approach for malaria control and eliminations efforts. However, its success depends on periodic assessment of local malaria vector behaviour. This study analysed entomological parameters to better understand malaria transmission in two different ecological settings of Mali: Dangassa in the Sudan savanna region along the Niger River and Koïla Bamanan in the Sahelian region that conducts rice cropping. In both areas, An. coluzzii species was predominant. This may not reflect the whole species composition picture as the samples treated by PCR for species identification were: (1) collected before the event of universal LLINs coverage and (2) were not separated by collection method (i.e. HLC vs PSC). Mosquito species composition could be affected by vector control measures [30,31] and could also vary according to the collection method. 


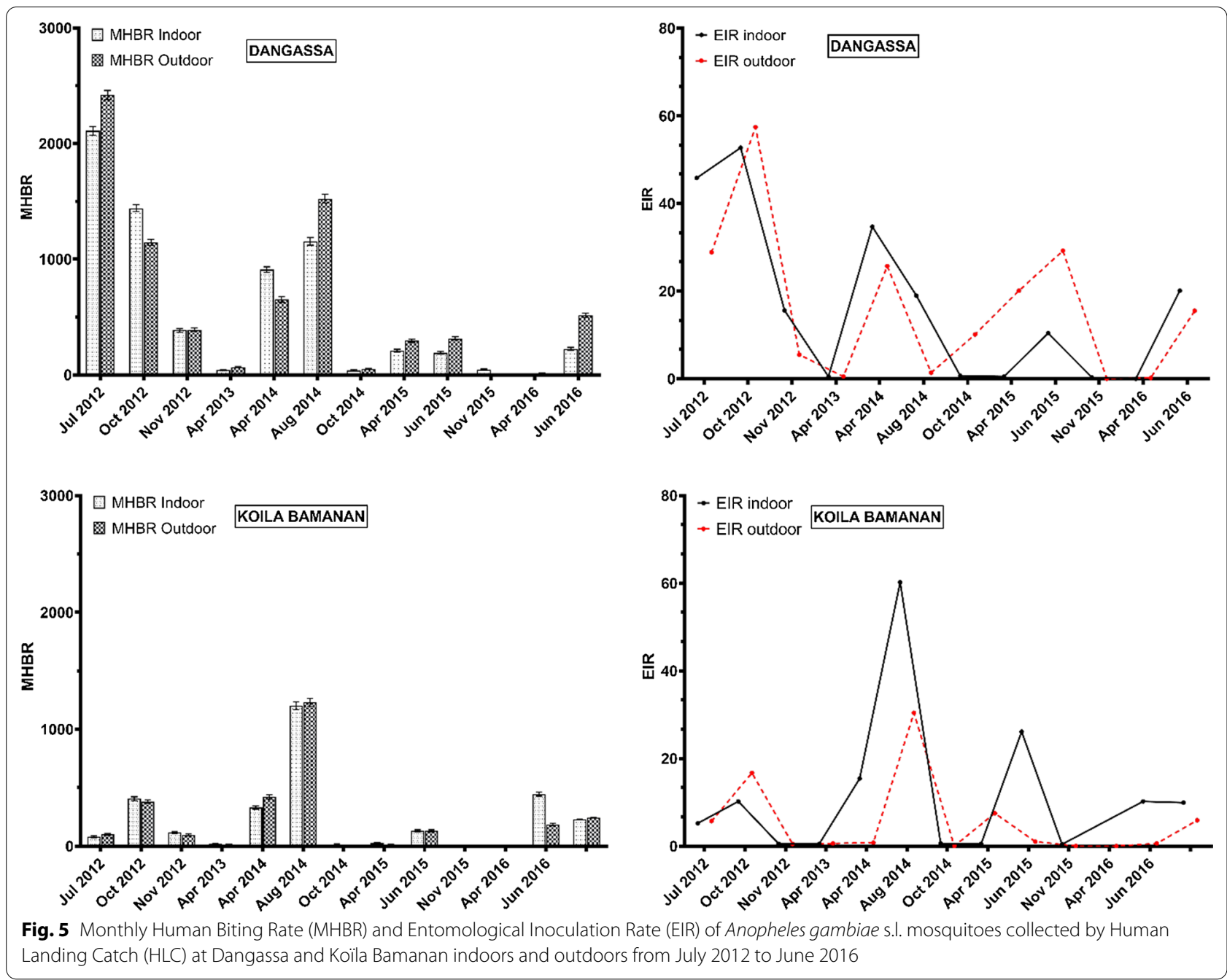

Previous studies conducted in Mali reported the predominance of this species in the Sudanese river savanna, flood prone and irrigated rice farming areas [32-35]. The authors explained their findings by the presence of favorable larval breeding sites to the development of this species such as ladder like brick pits, water puddles, ruts, flood prone plains and irrigated rice farming which were also common in our study sites. The highest density rates observed for Koïla Bamanan (twice) compared to Dangassa are most likely due to the rice cultivation which offers numerous suitable larval breeding habitats, especially during the earlier development stage of rice [36-38].

The mean densities were two times higher in Koïla Bamanan than in Dangassa. The density peaks are observed during the rainy season. However, another low amplitude peak other than that of the rainy season was observed in April in both localities. In Dangassa, the peak in the dry season could be explained by the availability of productive larval sites created in the river bed of River Niger when water recedes as reported by many studies across Africa [32, 34, 35, 39]. In Koïla Bamanan the dry season peak could be explained by vegetable cropping which creates suitable water puddles for larval development [40].

The outdoor human biting rates (HBR) were significantly higher than indoor biting rates. This could be due to the side effect of ongoing control measures like LLINs in these places as An. gambiae s.l. were known to be more endophagic than exophagic [41]. Indeed, several studies have shown changing its biting and resting behaviour from indoors to outdoors when LLINs were widely used in an area. Such an observation was also made in many African countries [35, 42-45]. However, recent data from Benin reported higher HBRs indoors than outdoors [41].

The human blood index (HBI) was significantly higher in Dangassa than in the irrigated rice farming area of Koilla Bamanan. This observation has now become 
Table 3 Sporozoite infection rate (SIR) of Anopheles gambiae s.l. mosquitoes collected by human landing catch indoors and outdoors in Dangassa and Koïla Bamanan from July 2012 to June 2016

\begin{tabular}{|c|c|c|c|c|c|c|c|c|}
\hline \multirow[t]{3}{*}{ Surveys } & \multicolumn{4}{|c|}{ Dangassa } & \multicolumn{4}{|c|}{ Koïla Bamanan } \\
\hline & \multicolumn{2}{|l|}{ Indoor } & \multicolumn{2}{|l|}{ Outdoor } & \multicolumn{2}{|l|}{ Indoor } & \multicolumn{2}{|l|}{ Outdoor } \\
\hline & \#Tested & IR (\%) BCI & \#Tested & IR (\%) BCI & \#Tested & IR (\%) BCI & \#Tested & IR (\%) BCI \\
\hline Jul 2012 & 232 & $2.2[0.7-4.4]$ & 88 & $1.2[0.0-4.3]$ & 16 & $6.5[0.2-22.1]$ & 18 & $5.7[0.2-19.8]$ \\
\hline Oct 2012 & 165 & $3.7[1.4-7.0]$ & 180 & $5.0[2.3-8.6]$ & 81 & $2.5[0.3-6.8]$ & 69 & $4.4[0.9-10.3]$ \\
\hline Nov 2012 & 75 & 4.0 [0.9-9.5] & 74 & $1.4[0.0-5.1]$ & 22 & $0.5[0.0-4.4]$ & 18 & $0.6[0.0-5.3]$ \\
\hline Apr 2013 & 7 & $1.4[0.0-13.0]$ & 12 & $0.8[0.0-7.8]$ & 4 & $2.3[0.0-22.1]$ & 2 & $4.3[0.0-41.9]$ \\
\hline Apr 2014 & 158 & $3.8[1.4-7.3]$ & 77 & $3.9[0.8-9.2]$ & 65 & 4.7 [1.0-10.9] & 56 & $0.2[0.0-1.8]$ \\
\hline Aug 2014 & 124 & $1.6[0.2-4.5]$ & 131 & $0.1[0.0-0.8]$ & 160 & $5.0[2.2-8.9]$ & 163 & $2.5[0.7-5.3]$ \\
\hline Oct 2014 & 5 & 1.8 [0.0-17.9] & 10 & $20.1[2.9-48.4]$ & 2 & $4.3[0.0-41.9]$ & 0 & 0.0 \\
\hline Apr 2015 & 41 & $0.3[0.0-2.4]$ & 59 & 6.8 [1.9-14.4] & 5 & 1.9 [0.0-18.0] & 2 & $50.0[2.7-97.2]$ \\
\hline Jun 2015 & 37 & $5.5[0.7-14.7]$ & 65 & $9.3[3.5-17.3]$ & 20 & 20.1 [6.1-39.6] & 13 & $0.8[0.0-7.2]$ \\
\hline Nov 2015 & 18 & $0.6[0.0-5.3]$ & 0 & 0 & 1 & $7.9[0.0-72.7]$ & 0 & 0.0 \\
\hline Apr 2016 & 2 & $4.3[0.0-41.8]$ & 6 & $1.6[0.0-15.1]$ & 0 & 0.0 & 0 & 0.0 \\
\hline Jun 2016 & 45 & 8.9 [2.6-18.7] & 101 & $3.0[0.6-7.1]$ & 89 & $2.3[0.3-6.2]$ & 30 & $0.4[0.0-3.3]$ \\
\hline Total & 909 & $3.1[2.1-4.3]$ & 803 & $3.6[2.4-5.0]$ & 465 & $4.3[2.7-6.3]$ & 371 & $2.4[1.1-4.2]$ \\
\hline
\end{tabular}

common in Mali as rice farming has been associated with lower HBI as demonstrated by many studies [36, 46]. The same observation has been reported in Senegal [47]. Explanation of this situation has been attributed to personal protection practices as the highest densities of $A n$. gambiae s.l. are known to occur in rice growing areas. Thus, mosquitoes are diverged to alternative hosts present in the area such as bovines, sheep, and goats as it is in Koïla Bamanan (unpublished observations by our study team). In addition, from 2008 to 2014, Koïla Bamanan was part of the Millennium Villages' Project where LLINs were freely distributed and replaced every 3 years. These practices significantly improved ownership and usage of LLINs which may have led to a behavioural change in trophic preference in the malaria vector. Many studies across Africa showed that anthropophagic and endophilic individuals could become zoophagic and exophilic from the intensification in the use of LLINs [16, 17, 31, 48, 49].

This study revealed a higher indoor than outdoor EIR at Koïla Bamanan. The inverse relationship was observed in Dangassa where outdoor EIR was higher than indoor EIR. These findings may be due to the higher outdoor HBR observed in Dangassa than in Koilla Bamanan. The higher outdoor HBR and EIR than indoors in Dangassa could be explained by prior findings that $A n$. gambiae s.l. is known to be anthropophagic and endophilic, but is becoming more exophilic and humans are staying outside houses longer and are bitten before going under mosquito nets. Other environmental factors, especially elevated ambient temperature, cause people to sleep with no protection against mosquito bites [41] or outdoors. In fact, several studies reported a high outdoor transmission rate $[35,42,50]$. This finding could be attributed to the use of LLINS distributed during prenatal screenings and mothers having completed the vaccination cycles of their babies who receive treated mosquito nets for free (since 2008). Also, the universal coverage in LLINS from May 2015 could itself cause mosquito behavioural changes.

\section{Conclusion}

Anopheles gambiae s.l. was more anthropophilic in Dangassa than in Koilla Bamanan. Both sites had comparable EIR outdoors and comparable indoor transmission which was also high at both sites. These findings have important implications for the epidemiology and strategies for control of malaria in the study area. Additional control strategies are needed to complement ongoing interventions to better address the issue of outdoor transmission and reduce indoor and outdoor resting vectors using the tool package offered by integrated vector management (IVM).

\section{Acknowledgements}

We also acknowledge the technical assistance and collaboration of Sekou Amadou Traoré, Daouda Niaré, Cheick Oumar Camara, Fousseyni Kané, Boissé Traoré, Cheick Amadou Coulibaly, Ayouba Diarra, Sidibé M'Baye Thiam and

Moussa Diallo. Our sincerest thanks to Gunter Muller and Amy Junnila for their contributions to the improvement of the manuscript. We thank all the ICEMR research team and the population of all the study sites for their collaboration. The study received support from the National Institutes of Allergy and Infectious Diseases (NIAID) through the West African International Center of Excellence for Malaria Research (ICEMR): NIAID U19 Al 089696 and U19 AI 129387 and through the NIH Fogarty International Center D43TW008652. 


\section{Authors' contributions}

MK, MC NS and SD designed the study and monitored its implementation. MK and NS analyzed and interpreted the results. MK, IS, MT, SID, DK conducted field work and contributed in laboratory analysis. MK wrote the manuscript which was critically revised by MC, NS, SFT, SD, ABS, JGS, DJK and MD. All authors read and approved the final manuscript.

\section{Funding}

This study was funded by the US National Institutes of Allergy and Infectious Diseases (NIAID) through the West African International Center of Excellence for Malaria Research (ICEMR): NIAID U19 AI 089696 and U19 AI 129387.

\section{Availability of data and materials}

The data used and/or analysed in this study are available from the corresponding author on reasonable request.

\section{Consent for publication}

Not applicable.

\section{Competing interests}

The authors declare that they have no competing interests.

\section{Author details}

${ }^{1}$ West African International Center of Excellence for Malaria Research, Bamako, Mali. ${ }^{2}$ Malaria Research and Training Center, Bamako, Mali. ${ }^{3}$ Faculty of Medicine and Odonto Stomatology, University of Sciences, Techniques and Technologies of Bamako, Bamako, Mali. ${ }^{4}$ Faculty of Science and Techniques, University of Sciences, Techniques and Technologies of Bamako, Bamako, Mali. ${ }^{5}$ School of Public Health and Tropical Medicine, Tulane University, 1440 Canal Street, New Orleans, LA 70112, USA.

Received: 3 September 2020 Accepted: 15 February 2021

Published online: 04 March 2021

\section{References}

1. Bejon P, Williams TN, Nyundo C, Hay SI, Benz D, Gething PW, et al. A microepidemiological analysis of febrile malaria in Coastal Kenya showing hotspots within hotspots. Elife. 2014;3:e02130.

2. Kang SY, Battle KE, Gibson HS, Cooper LV, Maxwell K, Kamya M, et al. Heterogeneous exposure and hotspots for malaria vectors at three study sites in Uganda. Gates Open Res. 2018;2:32.

3. WHO. Guidelines for malaria vector control. Geneva: World Health Organization; 2019.

4. Choi HW, Breman JG, Teutsch SM, Liu S, Hightower AW, Sexton JD. The effectiveness of insecticide-impregnated bed nets in reducing cases of malaria infection: a meta-analysis of published results. Am J Trop Med Hyg. 1995;52:377-82.

5. Bhatt S, Weiss DJ, Cameron E, Bisanzio D, Mappin B, Dalrymple U, et al. The effect of malaria control on Plasmodium falciparum in Africa between 2000 and 2015. Nature. 2015;526:207-11.

6. Keita M, Sogoba N, Traore B, Kane F, Coulibaly B, Traore SF, et al. Performance of pirimiphos-methyl based indoor residual spraying on entomological parameters of malaria transmission in the pyrethroid resistance region of Koulikoro, Mali. Acta Trop. 2021;216:105820.

7. Sy O, Niang EHA, Ndiaye M, Konate L, Diallo A, Ba ECC, et al. Entomological impact of indoor residual spraying with pirimiphos-methyl: a pilot study in an area of low malaria transmission in Senegal. Malar J. 2018;17(64):8

8. Piperaki E-T. Malaria eradication in the European World: historical perspective and imminent threats. In: Manguin S, Dev V, editors. Towards malaria elimination: a leap forward. London: IntechOpen; 2018.

9. Ba O, Ouldabdallahi M, Koita M, Sy O, Dahdi SA. Epidemiology of malaria and elimination prospects in Maghreb countries. Tunis Med. 2018;96:590-8.

10. Molina R, Benito A, Blanca F, Roche J, Otunga B, Alvar J. The Anophelines of Equatorial Guinea. Ethology and susceptibility studies. Res Rev Parasitol. 1996;56:105-10.

11. Pates H, Curtis C. Mosquito behavior and vector control. Annu Rev Entomol. 2005;50:53-70
12. Oyewole IO, Awolola TS, Ibidapo CA, Oduola AO, Okwa OO, Obansa JA. Behaviour and population dynamics of the major anopheline vectors in a malaria endemic area in southern Nigeria. J Vector Borne Dis. 2007;44:56-64.

13. Gillies MT, De Meillon B. The Anophelinae of Africa south of the Sahara (Ethiopian zoogeographical region), 2nd edn. Publ South Afr Inst Med Res. 1968:1-343.

14. Gillies MT, Coetzee M. A supplement to the Anophelinae of Africa South of the Sahara (Afrotropical region). Publ South Afr Inst Med Res. 1987;55:1-143.

15. Padonou GG, Sezonlin M, Osse R, Aizoun N, Oke-Agbo F, Oussou O, et al. Impact of three years of large scale indoor residual spraying (IRS) and insecticide treated nets (ITNs) interventions on insecticide resistance in Anopheles gambiae s.l. in Benin. Parasit Vectors. 2012;5:72.

16. Meyers Jl, Pathikonda S, Popkin-Hall ZR, Medeiros MC, Fuseini G, Matias A, et al. Increasing outdoor host-seeking in Anopheles gambiae over 6 years of vector control on Bioko Island. Malar J. 2016;15:239.

17. Russell TL, Govella NJ, Azizi S, Drakeley CJ, Kachur SP, Killeen GF. Increased proportions of outdoor feeding among residual malaria vector populations following increased use of insecticide-treated nets in rural Tanzania. Malar J. 2011;10:80

18. Mbogo CN, Baya NM, Ofulla AV, Githure Jl, Snow RW. The impact of permethrin-impregnated bednets on malaria vectors of the Kenyan coast. Med Vet Entomol. 1996;10:251-9.

19. Seyoum A, Sikaala CH, Chanda J, Chinula D, Ntamatungiro AJ, Hawela $M$, et al. Human exposure to anopheline mosquitoes occurs primarily indoors, even for users of insecticide-treated nets in Luangwa Valley. South-east Zambia. Parasit Vectors. 2012;5:101.

20. Lizzi KM, Qualls WA, Brown SC, Beier JC. Expanding integrated vector management to promote healthy environments. Trends Parasitol. 2014:30:394-400

21. Beier JC, Wilke AB, Benelli G. Newer approaches for malaria vector control and challenges of outdoor transmission. In: Manguin S, Dev V, editors. Towards malaria elimination: a leap forward. London: IntechOpen; 2018.

22. Castle S, Scott R, Mariko S. Malaria Prevention and Treatment for Children Under Five in Mali: Further Analysis of the 2012-13 Demographic and Health Survey. DHS Further Analysis Reports No. 93. Rockville, Maryland, USA: ICF International. 2014

23. Knols BG, de Jong R, Takken W. Differential attractiveness of isolated humans to mosquitoes in Tanzania. Trans R Soc Trop Med Hyg. 1995;89:604-6.

24. Okumu FO, Killeen GF, Ogoma S, Biswaro L, Smallegange RC, Mbeyela E, et al. Development and field evaluation of a synthetic mosquito lure that is more attractive than humans. PLOS ONE. 2010;5:e8951.

25. WHO. Manual on practical entomology in malaria/prepared by the WHO Division of Malaria and Other Parasitic Diseases. Geneva, World Health Organization, 1995. http://www.who.int/iris/handle/10665/42481.

26. Fanello C, Santolamazza F, della Torre A. Simultaneous identification of species and molecular forms of the Anopheles gambiae complex by PCRRFLP. Med Vet Entomol. 2002;16:461-4.

27. Beier JC, Perkins PV, Wirtz RA, Koros J, Diggs D, Gargan TP, et al. Bloodmeal identification by direct enzyme-linked immunosorbent assay (ELISA), tested on Anopheles (Diptera: Culicidae) in Kenya. J Med Entomol. 1988;25:9-16

28. Beier JC, Perkins PV, Wirtz RA, Whitmire RE, Mugambi M, Hockmeyer WT. Field evaluation of an enzyme-linked immunosorbent assay (ELISA) for Plasmodium falciparum sporozoite detection in anopheline mosquitoes from Kenya. Am J Trop Med Hyg. 1987;36:459-68.

29. Guindo A, Camara L, Dicko A, Traore SF, Coulibaly M, Coulibaly MB. Feeding behavior and insecticide resistance status of the Anopheles gambiae complex in prelude of indoors residual spraying in Baroueli, Mali. Int J Entomol Res. 2020;5:1-8.

30. Bayoh MN, Mathias DK, Odiere MR, Mutuku FM, Kamau L, Gimnig JE, et al. Anopheles gambiae: historical population decline associated with regional distribution of insecticide-treated bed nets in western Nyanza Province, Kenya. Malar J. 2010;9:62

31. Mwangangi JM, Mbogo CM, Orindi BO, Muturi EJ, Midega JT, Nzovu $J$, et al. Shifts in malaria vector species composition and transmission dynamics along the Kenyan coast over the past 20 years. Malar J. 2013;12:13 
32. Toure YT, Traore SF, Sankare O, Sow MY, Coulibaly A, Esposito F, et al. Perennial transmission of malaria by the Anopheles gambiae complex in a north Sudan Savanna area of Mali. Med Vet Entomol. 1996;10:197-9.

33. Dolo G, Briet OJ, Dao A, Traore SF, Bouare M, Sogoba N, et al. Malaria transmission in relation to rice cultivation in the irrigated Sahel of Mali. Acta Trop. 2004;89:147-59.

34. Sogoba N, Doumbia S, Vounatsou P, Baber I, Keita M, Maiga M, et al. Monitoring of larval habitats and mosquito densities in the Sudan savanna of Mali: implications for malaria vector control. Am J Trop Med Hyg. 2007;77:82-8

35. Keita M, Baber I, Sogoba N, Maiga HM, Diallo M, Doumbia S, et al. Vectorial transmission of malaria in a village along the Niger River and its fishing hamlet (Kenieroba and Fourda, Mali) (in French). Bull Soc Pathol Exot. 2014;107:356-68.

36. Diuk-Wasser MA, Toure MB, Dolo G, Bagayoko M, Sogoba N, Traore SF, et al. Vector abundance and malaria transmission in rice-growing villages in Mali. Am J Trop Med Hyg. 2005;72:725-31.

37. Diuk-Wasser MA, Toure MB, Dolo G, Bagayoko M, Sogoba N, et al. Effect of rice cultivation patterns on malaria vector abundance in rice-growing villages in Mali. Am J Trop Med Hyg. 2007;76:869-74.

38. Sogoba N, Vounatsou P, Bagayoko MM, Doumbia S, Dolo G, Gosoniu L, et al. The spatial distribution of Anopheles gambiae sensu stricto and An. arabiensis (Diptera: Culicidae) in Mali. Geospat Health. 2007;1:213-22.

39. Mouchet J. Influence des fleuves sur la biologie d'Anopheles gambiae pendant la saison sèche dans le Sud-Cameroun. Bull Soc Pathol Exot. 1962;55:1163-71.

40. Talom AD, Essoung MA, Gbankoto A, Tchigossou G, Akoton R, et al. A preliminary analysis on the effect of copper on Anopheles coluzzii insecticide resistance in vegetable farms in Benin. Sci Rep. 2020;10:6392.

41. Salako AS, Ahogni I, Kpanou C, Sovi A, Azondekon R, Sominahouin AA, et al. Baseline entomologic data on malaria transmission in prelude to an indoor residual spraying intervention in the regions of Alibori and Donga, Northern Benin, West Africa. Malar J. 2018;17:392.

42. Degefa T, Yewhalaw D, Zhou G, Lee MC, Atieli H, Githeko AK, et al. Indoor and outdoor malaria vector surveillance in western Kenya: implications for better understanding of residual transmission. Malar J. 2017;16:443.
43. Overgaard HJ, Reddy VP, Abaga S, Matias A, Reddy MR, Kulkarni V, et al Malaria transmission after five years of vector control on Bioko Island, Equatorial Guinea. Parasit Vectors. 2012;5:253.

44. Bayoh MN, Walker ED, Kosgei J, Ombok M, Olang GB, Githeko AK, et al. Persistently high estimates of late night, indoor exposure to malaria vectors despite high coverage of insecticide treated nets. Parasit Vectors. 2014;7:380.

45. Fredrick Kabbale AA, Kaddu J, Matovu E, Onapa A. Biting times of Plasmodium falciparum infected mosquitoes and transmission intensities following five years of insecticide-Treate bed nets use in Kamuli District, Uganda: implications for malaria control. Int J Mosq Res. 2016;3:30-8.

46. Sogoba N, Vounatsou P, Doumbia S, Bagayoko M, Toure MB, Sissoko IM, et al. Spatial analysis of malaria transmission parameters in the rice cultivation area of Office du Niger, Mali. Am J Trop Med Hyg. 2007;76:1009-15.

47. Konate L, Faye O, Gaye O, Sy N, Diop A, Diouf M, et al. Zoophagia and alternative host selection of the marlaia vectors in Senegal. Parasite. 1999;6:259-67.

48. Lefevre T, Gouagna LC, Dabire KR, Elguero E, Fontenille D, Renaud F, et al. Beyond nature and nurture: phenotypic plasticity in blood-feeding behavior of Anopheles gambiae s.s. when humans are not readily accessible. Am J Trop Med Hyg. 2009;81:1023-9.

49. Reddy MR, Overgaard HJ, Abaga S, Reddy VP, Caccone A, Kiszewski AE, et al. Outdoor host seeking behaviour of Anopheles gambiae mosquitoes following initiation of malaria vector control on Bioko Island, Equatorial Guinea. Malar J. 2011;10:184.

50. Durnez L, Mao S, Denis L, Roelants P, Sochantha T, Coosemans M. Outdoor malaria transmission in forested villages of Cambodia. Malar J. 2013;12:329.

\section{Publisher's Note}

Springer Nature remains neutral with regard to jurisdictional claims in published maps and institutional affiliations.
Ready to submit your research? Choose BMC and benefit from:

- fast, convenient online submission

- thorough peer review by experienced researchers in your field

- rapid publication on acceptance

- support for research data, including large and complex data types

- gold Open Access which fosters wider collaboration and increased citations

- maximum visibility for your research: over $100 \mathrm{M}$ website views per year

At BMC, research is always in progress.

Learn more biomedcentral.com/submissions 